\title{
Content is king
}

\author{
Fiona Godlee editor, The BMJ
}

We're continuing to mark the 20 years since The BMJ launched itself on the internet. In 1995, with the then web editor, Tony Delamothe, at the helm, bmj.com was innovative simply by being the first medical journal website. Under our digital editor, David Payne, it has continued to lead the way, aiming to offer readers the very best access, interaction, and experience that technology can provide.

But rather than itemising these developments and plans, we have chosen to celebrate this 20th anniversary by highlighting the content hosted on the website in the past two decades. Twenty readers and contributors have each chosen one outstanding article, and the result is our top 20. As David Payne says (doi:10.1136/bmj.h3660), they are "an extraordinary mix of editorials, research papers, analysis, and comment, including an investigation, on topics as wide ranging as the MMR vaccine scare, death, evidence based medicine, and the use of stirrups for pelvic examinations."

We invite you to vote for your favourite of the six most highly cited of these 20 articles (thebmj.com/thebmj), to look through the ones that got away (thebmj.com/content/351/bmj.h3660/rr), and to tell us in a rapid response what you would have chosen.

I've already made my top 20 selection, but I'll take this opportunity to list some more of my favourites from the past two decades - this is Editor's Choice, after all. Victor Montori and colleagues changed how I thought when they introduced me to the idea of minimally disruptive medicine (doi:10.1136/ bmj.b2803). Beata Wieseler and colleagues showed us what a courageous regulator can do when IQWiG, Germany's equivalent of the UK National Institute for Health and Care Excellence (NICE), insisted on being given access to, and then analysed, all the data on reboxetine (doi:10.1136/bmj.c4942). Peter Gøtzsche and colleagues set the standard for articles to be published in our then new Analysis section-well written, hard hitting, evidence based, and controversial—when they reported on the failure of patient information leaflets to give the whole story about mammography (doi:10.1136/bmj.b86). And for me the most iconic of all: the articles that uncovered and then analysed the hidden data on oseltamivir (Tamiflu) (thebmj. com/tamiflu).

Talking of iconography, it is perhaps a little ironic that we have chosen to illustrate our celebration of the website's first 20 years with images of the print magazine's covers. Despite our embrace of the digital age, it's clear that print is far from dead, and we are now fully redesigning the print journal for the first time since 2007. The new design-more readable, browsable, colourful, engaging, and informative-will be launched in the autumn. If you'd like to help by giving us your views on some prototypes, please contact Jonathan Black (jblack@bmj.com). More images will be a feature of the new look, in print and online. The infographics that accompanied the latest mammoth NICE guidance on referral for suspected cancer are an example of what's in store (doi:10.1136/bmj.h3036; doi:10.1136/bmj. h3044). In his editorial about the guidance this week, Kevin Barraclough has high praise but also some reservations (doi:10. 1136/bmj.h3640). There is no doubting the scholarship and evidence base behind the guidance, he says. But will lowering the threshold for referral to a positive predictive value of $3 \%$ mean that he will retire from general practice only to spend his remaining years being investigated in hospital outpatient clinics? I conclude from all this that content is king, images are the future, and minimally disruptive medicine must be our goal. 